\title{
Tinjauan Sistem Penyelenggaraan Rekam Medis Menurut Standart Akreditasi Puskesmas di Puskesmas Pangakalan Berandan Tahun 2020
}

\author{
Esraida Simanjuntak ${ }^{1}$, Fajar Insani ${ }^{2}$ \\ ${ }^{1,2}$ Program Studi D3 Perekam dan Informasi Kesehatan, Universitas Imelda Medan
}

\begin{tabular}{l}
\hline Article Info \\
\hline Article history: \\
Received July 03, 2021 \\
Revised July 16, 2021 \\
Accepted July 19, 2021
\end{tabular}

Keywords:

Organizing Medical Records Puskesmas

Accreditation Standards

\begin{abstract}
Puskesmas are required to maintain medical records containing data and information on patient care. Implementation according to accreditation standards, namely criteria 3.2 Registration Process and 3.8 Administration of medical records which are divided into 3.8.1 Coding, 3.8.2 Medical Record Access Rights 3.8.3 Clinical Information Filling and 3.8.4 Storage. The purpose of the study was to find out the implementation medical record management system according to the Puskesmas accreditation standards at the Pangkalan Berandan Health Center in 2020. This type of research was qualitative with a Phenomenology approach. The place of research was conducted at the Pangkalan Berandan Health Center. Time of study in July 2020. Research population is all medical record officers at the Pangkalan Berandan Health Center. The research sample is 5 officers. The research instrument was interview guide and check list sheet for observation. The results of the study revealed that the outpatient registration process had been carried out according to criteria 3.2 but there was no inpatient numbering of medical records. Coding was not carried out according to criteria 3.8.1, namely the absence of coding SOPs carried out by doctors using ICD 10, Medical Record Access Rights were carried out according to criteria 3.8. 2 but the implementation is not fully carried out in accordance with the SOP, the lending process is not recorded in the expedition book, Assembling is in accordance with criteria 3.8.3 but recording corrections are carried out using stip-ex and the storage process has been carried out according to criteria 3.8.4 but retention is not carried out according to the guidelines legislation. It is recommended for registration to give medical record numbers to inpatients, coding to make SOPs and given coding training, access rights to medical records to record loans in expedition books, assembling to be given socialization in terms of correcting recording of medical record files and storing tracers as well as in the retention process. given socialization about the implementation of retention.
\end{abstract}

This is an open access article under the CC BY-SAlicense.
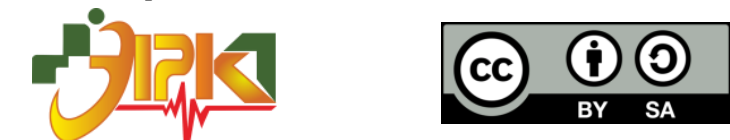

\section{Corresponding Author:}

Esraida Simanjuntak,

Program Studi D3 Perekam dan Informasi Kesehatan,

Universitas Imelda Medan,

Jl. Bilal No. 52 Kelurahan Pulo Brayan Darat I Kecamatan Medan Timur, Medan - Sumatera Utara.

Email: esraida.borjun@gmail.com 


\section{PENDAHULUAN}

Menurut Permenkes Republik Indonesia Nomor 43 tahun 2019 [1], Puskesmas adalah fasilitas pelayanan kesehatan yang menyelenggarakan upaya kesehatan masyarakat dan kesehatan perseorangan tingkat pertama melalui upaya promosi dan pencegahan yang diprioritaskan untuk mencapai derajat kesehatan masyarakat yang setinggi-tingginya di wilayah tempatnya bekerja. Dalam melaksanakan fungsi penyelenggaran upaya kesehatan perseorangan tingkat awal di wilayah kerjanya Puskesmas berwenang untuk melaksanakan penyelenggaraan rekam medis.

Dalam Standar Akreditas Puskesmas penyelenggaraan rekam medis diatur berdasarkan Peraturan Menteri Kesehatan pada Lampiran I tentang Standart dan Instrumen Akreditasi Puskesmas Edisi Kedua, versi tahun 2019 [2] yang terdiri dari lima (5) bagian pelayanan di Pusat Kesehatan Masyarakat. Salah satu kriteria yang memuat penilaian tentang penyelenggaran rekam medis terdapat pada kriteria 3.2 yaitu Proses pendaftaran dan 3.8 yaitu Penyelenggaraan rekam medis. Puskesmas wajib menyelenggarakan rekam medis yang berisi informasi data pasien yang dibutuhkan untuk pelayanan pasien, dan dapat diakses oleh petugas kesehatan pemberian asuhan manajemen, dan pihak di luar organisasi yang diberi hak akses terhadap rekam medis untuk kepentingan pasien, asuransi, sesuai peraturan perundang-undangan serta adanya jaminan ketersediaan informasi melalui terselenggaranya sistem menajemen data dan informasi di Puskesmas.

Dipuskesmas yang menyelenggarakan rekam medis, terdapat proses pendaftaran pasien yang dilakukan dengan mempertimbangkan kebutuhan dan keamaan pelanggan, serta didukung oleh fasilitas dan lingkungan yang memadai. Kode klasifikasi diagnostik, kode program, simbol, dan istilah yang digunakan semuanya distandarisasi. Setiap kader dapat mengakses informasi sesuai dengan kebutuhan dan tanggung jawab pekerjaannya, memiliki pengisian rekam medis yang lengkap dan jelas dalam sistem informasi klinis, serta memiliki sistem untuk memandu penyimpanan dan pengolahan rekam medis.

Berdasarkan hasil survei awal yang telah dilakukan di Puskesmas Pangkalan Berandan diketahui bahwa Puskesmas sudah terakreditasi dengan status pelayanan kesehatan dasar pada tahun 2018 akan tetapi dalam hal penyelenggaraan rekam medis masih ditemukan tidak adanya penomoran rekam medis pada berkas rawat inap sangat tidak sesuai dengan kriteria 3.2.1 yang terdapat pada proses pendaftaran dalam hal keselamatan pasien yang harus diperhatikan sejak awal pasien kontak langsung dengan pusat kesehatan masyarakat., terutama dalam hal identifikasi pasien dengan minimal 2 identitas yang relatif tidak berubah yaitu nama lengkap pasien, tanggal lahir atau nomor rekam medis.

Selain itu, tidak terdapat juga panduan pada proses pelaksanaan pengkodingan hal ini berarti tidak sesuai dengan eleman penilaian yang terdapat pada kriteria 3.8.1 yaitu adanya kode klasifikasi diagnostik, kode program, simbol, dan istilah yang digunakan. Tidak dapat diselenggarakannya rekam medis yang tidak sesuai dengan prosedur dan pedoman akreditasi puskesmas maka akan dapat mengakibatkan ketidaksinambungan terhadap sistem manajemen dan sistem pelayanan serta program yang terdapat di Puskesmas. Berdasarkan hal tersebut penulis tertarik untuk melakukan penelitian dengan topik "Tinjauan Sistem Penyelenggaraan Rekam Medis Menurut Standart Akreditasi Puskesmas di Puskesmas Pangakalan Berandan Tahun 2020".

\section{METODE PENELITIAN}

\section{A. Jenis Penelitian}

Penelitian ini dilakukan menggunakan metode kualitatif dengan pendekatan Phenomenology yang bertujuan untuk memperoleh informasi secara mendalam mengenai Penyelenggaraan Rekam Medis di Pusat Kesehatan Masyarakat Pangkalan Berandan. 
B. Subyek Penelitian

Subyek Penelitian ialah informan yang dijadikan teman ataupun konsultan untuk menggali informasi yang dibutuhkan peneliti [3]. Adapun subyek dalam penelitian ini adalah semua pekerja rekam medis di Puskesmas Pangkalan Berandan sebanyak 5 orang.

C. Instrumen Penelitian

Instrumen yang digunakan ialah melalui wawancara dan pedoman lembar check list untuk dapat di observasi kembali oleh peneliti.

D. Cara Pengumpulan Data

1. Data Primer

Data primer yang dapaat langsung dari petugas rekam medis melalui wawancara dan hasil observasi.

2. Data Sekunder

Data sekunder yaitu data yang sudah ada yaitu profil puskesmas, kebijakan dan SOP yang ada di Puskesmas serta penelitian sebelumnya.

E. Analisis Data

Data yang diperoleh dari wawancara dilakukan secara manual sesuai dengan petunjuk pengolahan data kualitatif serta sesuai dengan tujuan penelitian ini kemudian diinterprestasikan dan disajikan dalam bentuk narasi.

\section{HASIL DAN PEMBAHASAN}

\subsection{Hasil}

Sistem penyelenggaraan rekam medis di Puskesmas Pangkalan Berandan sebagai berikut:

Tabel 1. Hasil Observasi Pendaftaran di Puskesmas Pangkalan Berandan

\begin{tabular}{llll}
\hline No Pengamatan & \multicolumn{1}{c}{ Keterangan } & Ya & Tidak \\
\hline & $\begin{array}{l}\text { Adanya SOP sebagai pedoman pada pendaftaran } \\
\text { rawat jalan dan rawat inap. }\end{array}$ & $\sqrt{ }$ \\
& $\begin{array}{l}\text { Terdapat alur untuk pasien yang mendaftar ke } \\
\text { pendaftaran rawat jalan atau rawat inap. }\end{array}$ & $\sqrt{ }$ \\
& $\begin{array}{l}\text { Pada saat mendaftar pasin mendapatkan informasi } \\
\text { tentang sarana pelayanan seperti tarif, jenis }\end{array}$ & $\sqrt{ }$ \\
& $\begin{array}{l}\text { pelayanan, alur dan proses pendaftaran, alur dan } \\
\text { proses pelayanan serta sistem rujukan. }\end{array}$ & \\
& $\begin{array}{l}\text { Petugas membuat kartu identitas berobat untuk } \\
\text { pasien baru. }\end{array}$ & $\sqrt{ }$ \\
& $\begin{array}{l}\text { Petugas menyiapkan berkas rekam medis pasien. } \\
\text { Pendaftaran rekam medis dikirim ke poliklinik oleh } \\
\text { petugas rekam medis. }\end{array}$ & $\sqrt{ }$ \\
\hline & $\begin{array}{l}\text { Petugas mencatat dalam buku register pasien rawat } \\
\text { jalan/rawat inap. }\end{array}$ & $\sqrt{ }$ \\
& $\begin{array}{l}\text { Terdapat Kartu Indeks Utama Pasien (KIUP) } \\
\text { untuk memudahkan pencarian berkas rekam medis } \\
\text { apabila pasien tidak membawa kartu identitas } \\
\text { berobat. }\end{array}$ & \\
\hline
\end{tabular}

Hasil Observasi yang dilakukan oleh peneliti sejalan dengan hasil wawancara dengan salah satu informan. Berikut kutipan wawancara dari salah satu informan:

"SOP rawat jalan aja yang ada untuk rawat inapnya nggak ada. Kami juga ngikutin dari SOPnya, untuk pasien BPJS pasiennya datang ke tempat pendaftaran lalu dikasih nomor antrian terus nanti dipanggil sama petugas disini pakai mic, nanti petugas 
minta kartu BPJS terus dilihatlah di komputer apakah BPJSnya masih aktif atau engga. kalau masih aktif ya langsung kita lihat aja dikartu BPJS nomor rekam medisnya karena biasanya kami menuliskan nomor rekam medisnya di kartu BPJS. Kalau untuk pasien baru ya dibuat no rekam medisnya yang baru lalu dicatat di buku register terus ditanya apa keluhannya abis itu diarahkanlah pasiennya untuk menunggu di poli. yaudah nanti petugas disini yang ngantar berkasnya ke polinya" (Informan R, 41 tahun, wawancara: 27 Juli) informan:

Sedangkan prosedur untuk pendaftaran pasien umum, berikut kutipan dari salah satu

"SOP rawat jalan doang yang ada rawat inapnya coba nanti tanya sama orang UGD aja, ibu rasa nggak ada di map ini, kan kalau pasien umum tinggal minta aja kartu berobatnya abis itu langsung kita lihat berapa nomor rekam medisnya terus cariklah di raknya. nanti tanyakkanlah keluhan pasiennya apa abis itu langsung kita arahkan aja ke polinya. bedanya sama pasien baru hanya di pembuatan nomor rekam medisnya aja terus kita catat dibuku register sekalianlah buat berkas barunya juga nanti tanyakan langsung keluhannya apa, yaudah kita arahkan lagi kepoli. Petugas disini nanti yang ngantar berkas rekam medisnya ke poli” (Informan MR, 44 tahun, wawancara: 27 Juli 2020).

Terdapat juga alur yang memudahkan pasien dalam proses pendaftaran rawat jalan dan rawat inap di Puskesmas Pangkalan Berandan. Berikut kutipan wawancara dari salah satu Informan :

"Ada, itu alurnya ada di depan apotik. Sebenarnya dulu ruangan pendaftaran ini apotik cuman dipindahkan, diroker gitu karnakan ruangan ini besar jadi bisa menampung banyak untuk penyimpanan berkasnya tapi masih nampaknya itu alurnya” (Informan JA, 53 tahun, wawancara: 27 Juli 2020).

Tabel 2. Hasil Observasi Pendaftaran di Puskesmas Pangkalan Berandan

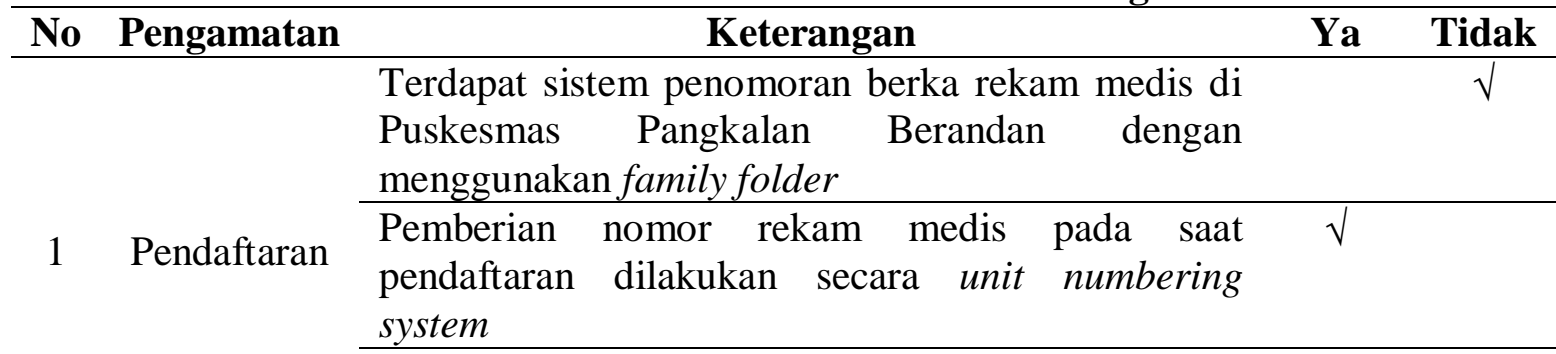

Terdapat sistem penamaan pada berkas rekam medis menggunakan Ny, Tn, Nn dan By.

Hasil observasi yang dilakukan oleh peneliti juga sejalan dengan hasil wawancara dengan salah satu informan. Berikut kutipan wawancara dari salah satu informan :

"Penomorannya disini setiap pasien mendapatkan satu nomor rekam medis bukan menggunakan family folder lagi tapi sistem kode wilayahnya masih tetap dipakai. Disini ada 5 kode wilayah 01 untuk kelurahan pelawi utara, 02 untuk berandan timur baru, 03 berandan timur, 04 berandan barat dan 05 ini untuk diluar wilayah. Waktu sebelum akreditas kemarin memang masih menggunakan family folder cuman karna berkasnya banyak yang hilang dan berusakan makanya diganti jadi setiap satu orang satu rekam medis yang digunakan untuk selamanya" (Informan S, 45 tahun, wawancara: 27 Juli 2020).

Sedangkan untuk sistem penomoran rekam medis rawat inap masih belum terdapat sistem penomoran rekam medisnya. Berikut kutipan wawancara dari salah satu informan :

"Penomoran untuk rawat inap nggak ada, biasanya ditulis sama perawatnya itu nomor kartu BPJS pasiennya. Lagian untuk penyimpanan rawat inap disini masih berserakan. Namanya disini nggak ada yang bener-bener tamatan rekam medis terus 
pas akreditas kemarin semua pada sibuk fokus sama prokjanya masing-masinglah yang di ruangan pendaftaran juga berkasnya masih banyak yang berhilangan dan berserakan. Jadi enggak mungkinlah kami tinggalkan yang disini makanya kami enggak sempat untuk memperbaiki berkas yang rawat inapnya" (Informan R, 41 tahun, wawancara: 27 Juli 2020).

Selain itu, untuk sistem penamaan di Puskesmas Pangkalan Berandan juga tidak menggunakan sistem penamaan dengan menggunakan kata depan $\mathrm{Ny}, \mathrm{Nn}$, Tn, dan By. Berikut kutipan wawancara dari salah satu informan:

"kan sewaktu mau mendaftar di pendaftaran kita akan minta KTP nya yaudah lihat aja dari KTP nya namanya terus pastikan lagi dengan menyebutkan namanya, kalau benar yaudah kita tulis aja langsung diberkas rekam medis sama formulirnya" (Informan HS, 44 tahun wawancara: 27 Juli 2020).

Tabel 3. Hasil Observasi Pendaftaran di Puskesmas Pangkalan Berandan

\begin{tabular}{|c|c|c|c|c|}
\hline No & Pengamatan & Keterangan & Ya & Tidak \\
\hline \multirow{3}{*}{1} & \multirow{3}{*}{ Pendaftaran } & $\begin{array}{l}\text { Pasien dengan kendala atau berkebutuhan khusus } \\
\text { diidentifikasi dan difasilitas agar dapat } \\
\text { memperoleh pelayanan klinis yang optimal }\end{array}$ & $\sqrt{ }$ & \\
\hline & & $\begin{array}{l}\text { Pasien gawat darurat diberikan prioritas untuk } \\
\text { asesmen sebagai bentuk pelaksanaan triase }\end{array}$ & $\sqrt{ }$ & \\
\hline & & $\begin{array}{l}\text { Ditetapkannya pedoman dan prosedur tentang } \\
\text { pelaksanaan proses triase dalam memprioritaskan } \\
\text { pasien dengan kebutuhan gawat durat }\end{array}$ & $\sqrt{ }$ & \\
\hline
\end{tabular}

Hasil observasi yang dilakukan oleh peneliti sejalan dengan hasil wawancara dengan salah satu informan. Berikut kutipan wawancara dari salah satu informan :

"itu kita lihat-lihat juga pasiennya kalau pasiennya memang udah kesakitan kali ya harus kita deluankan dulu walaupun no antriannya paling belakang, abis itu kita bawa langsung UGD kalau nggak bisa ditangani juga langsung di rujuk" (Informan MR, 44 tahun, wawancara: 27 Juli 2020).

Sedangkan untuk pelaksanaan proses triase pada pasien gawat darurat berikut kutipan wawancara dari salah satu informan :

"Kalau pelaksanaan triase sesuai tingkat kegawat darurat pasiennya di UGD sini enggak ada. Semua pasien yang gawat ya dilayani enggak ada dibeda-bedakan kayak di rumah sakit, tapi tetap ada sekat-sekatnya juga untuk ruang tindakan ada ruang resusitasinya ada cuman tetap SOPnya itu ada, lihat aja di UGD nanti SOPnya pasti ada. Cuman pelaksanaanya enggak ada disini" (Informan JA, 53 tahun, wawancara: 27 Juli 2020).

Tabel 4. Hasil Observasi Pengkodingan di Puskesmas Pangkalan Berandan

\begin{tabular}{|c|c|c|c|c|}
\hline No & Pengamatan & Keterangan & Ya & Tidak \\
\hline \multirow{5}{*}{2} & \multirow{5}{*}{ Pengkodingan } & $\begin{array}{lll}\text { Ditetapkan } & \text { standarisasi/pembakuan } & \text { kode }\end{array}$ & & \\
\hline & & $\begin{array}{l}\text { klasifikasi diagnosis, kode klasifikasi tindakan, } \\
\text { terminologi lain, singkatan-singkatan yang boleh } \\
\text { dan tidak boleh digunakan dalam pelayanan klinis }\end{array}$ & & $\sqrt{ }$ \\
\hline & & $\begin{array}{l}\text { Pengkodingan dilakukan oleh petugas rekam } \\
\text { medis. }\end{array}$ & & $\sqrt{ }$ \\
\hline & & $\begin{array}{l}\text { Pengkodingan dilakukan menggunakan ICD } 10 \\
\text { dan ICD CM } 9 \text { sebagai prosedur/tindakan. }\end{array}$ & $\sqrt{ }$ & \\
\hline & & $\begin{array}{l}\text { Adanya SOP yang menjadi pedoman petugas } \\
\text { dalam melakukan pengkodingan berkas rekam } \\
\text { medis. }\end{array}$ & & $\sqrt{ }$ \\
\hline
\end{tabular}


Berdasarkan hasil wawancara terkait pengkodingan pada kriteria 3.8.1 yang terdapat di Puskesmas Pangkalan Berandan memperoleh informasi yaitu:

"kalau kode penyakitnya ya pasti udah ditetapkan. Lagian dokter juga udah pasti tau itu kalau masalah terminologi penyakit gitu. tapi kalau SOPnya emang nggak ada karna kami kurang tau kode-kode penyakit gitu" (Informan R, 41 tahun,wawancara: 27 Juli 2020).

Berikut kutipan wawancara dari salah satu informan tentang tata cara pelaksanaan pengkodingan di Puskesmas Pangkalan Berandan :

"ya biasanya kalau udah diisi statusnya sama perawatnya nanti dokter yang akan mengisi kode penyakitnya. Udah tau itu perawatnya kalo kode kek gitu dokter yang bahkan ngisi. Kalau lagi banyak pasien dokter akan ngisinya diatas jam 12.00 karnakan disitu udah mulai sedikit pasiennya. Biasanya dokter nyarik kodenya itu pakek buku tebal kayak kamus gitu, ICD 10 gitu namanya kalau nggak salah tapi jarang dokter bukak itu karnakan udah hapal dokter kode penyakitnya, lagiankan di sini itu-itu aja penyakitnya ISPA, diaere jadi tinggal diisi langsung sama dokter tapi kalau dokter nggaktau kodenya baru dilihat dokter dari situ. Habis diisi lengkap nanti statusnya barulah dientry sama petugasnya kedalam komputer, komputernya itu terhubung sama komputer bpjs yang diatas terus ya urusan orang atas itu nanti, dijadikan laporan terus diklaim untuk pencairan BPJS, ya pokoknya orang itulah yang tau” (Informan JA, 53 tahun, wawancara: 27 Juli 2020).

Tabel 5. Hasil Observasi Hak Akses Rekam Medis di Puskesmas Pangkalan Berandan

\begin{tabular}{|c|c|c|c|c|}
\hline No & Pengamatan & Keterangan & Ya & Tidak \\
\hline \multirow{3}{*}{3} & \multirow{3}{*}{$\begin{array}{l}\text { Hak Akses } \\
\text { Rekam Medis }\end{array}$} & $\begin{array}{l}\text { Adanya SOP yang menjadi pedoman peminjaman } \\
\text { dan pengembalian berkas rekam medis }\end{array}$ & $\sqrt{ }$ & \\
\hline & & $\begin{array}{l}\text { Peminjaman berkas rekam medis menggunakan } \\
\text { bon peminjaman lalu dicatat menggunakan buku } \\
\text { ekspedisi }\end{array}$ & & \multirow[t]{2}{*}{$\sqrt{ }$} \\
\hline & & $\begin{array}{l}\text { Pengembalian berkas rekam medis dilakukan } \\
\text { kurang dari } 1 \text { x } 24 \text { jam }\end{array}$ & $\sqrt{ }$ & \\
\hline
\end{tabular}

Hasil observasi yang dilakukan oleh peneliti sejalan dengan hasil wawancara dengan salah satu informan. Berikut kutipan wawancara dari salah satu informan:

"ada, setiap ruangan disini memiliki SOPnya masing-masing, seharusnya memang SOPnya ditempelkan didinding kayak ruangan lain, cuman karena ruangan pendaftaran baru dipindahkan ya jadi masih belum kami lengketkan" (Informan JA, 53 tahun, wawancara: 27 Juli 2020).

Untuk pelaksanaan peminjaman berkas rekam medis tidak menggunakn Bon peminjaman. Berikut kutipan wawancara dari salah satu informan :

"jarang berkas rekam medis dipinjam, paling kalau dipinjam pun sama orang poli karna ada kelupaan mereka ngentry datanya tapi itu sebentar minjamnya, misalnya pagi gitu minjamnya nanti pas mau pulang kerja ya dikembalikan lagi sama mereka. Cara minjamnya pun yaudah mereka datang kesini nanti diambil mereka langsung statusnya dirak cuman mereka pasti bilang sama kami disini. Jadi kami tau siapa yang minjamnya” (Informan S, 41 tahun, wawancara: 27 Juli 2020).

"paling misalnya ada anak PKL gitu kayak perawat atau bidan, biasanya mereka yang minjam untuk laporan askep. Itupun mereka ngeliat statusnya pas diruang poli, udah sunyi pasien yang berobat ya disitu mereka lihat berkasnya. Kalaupun ada yang kurang-kurang nanti, baru mereka ngeliatnya kesini, itupun langsung mereka catat dibuku mereka, jadi nggak dibawa kemana-mana, tetap disini juga mereka mencatatnya” (Informan R, 41 tahun, wawancara: 27 Juli 2020). 
Tabel 6. Hasil Observasi Assembling di Puskesmas Pangkalan Berandan

\begin{tabular}{|c|c|c|c|c|}
\hline No & Pengamatan & Keterangan & Ya & Tidak \\
\hline \multirow{6}{*}{4} & \multirow{6}{*}{ Assembling } & $\begin{array}{l}\text { Terdapat kebijakan dan prosedur dalam pengisian } \\
\text { rekam medis mencakup dignosisis, pengobatan, } \\
\text { hasil pengobatan sebagai pedoman petugas. }\end{array}$ & & \\
\hline & & $\begin{array}{lll}\text { Dilakukannya assembling } & \text { (Perakitan) } & \text { di } \\
\text { Puskesmas Pangkalan Berandan } & & \end{array}$ & $\sqrt{ }$ & \\
\hline & & $\begin{array}{l}\text { Dokter, perawat, bidan dan petugas pemberi } \\
\text { asuhan yang lain bersama-sama menyepekati isi } \\
\text { rekam medis sesuai dengan kebutuhan informasi } \\
\text { yang perlu ada dalam pelaksanaan asuhan pasien }\end{array}$ & $\sqrt{ }$ & \\
\hline & & $\begin{array}{l}\text { Rekam medis diisi oleh setiap dokter, dokter gigi } \\
\text { dan tenaga kesehatan yang melaksanakan } \\
\text { pelayanan kesehatan di Puskesmas Pangkalan } \\
\text { Berandan. }\end{array}$ & $\sqrt{ }$ & \\
\hline & & $\begin{array}{l}\text { Rekam medis segera dicatat lengkap dan jelas } \\
\text { setelah pasien menerima pelayanan serta } \\
\text { mencantumkan nama waktu dan tanda tangan } \\
\text { dokter, dokter gigi dan tenaga kesehatan yang } \\
\text { memberikan pelayanan di Puskesmas Pangkalan } \\
\text { Berandan. }\end{array}$ & $\sqrt{ }$ & \\
\hline & & $\begin{array}{l}\text { Dalam hal terjadi kesalahan dalam pencatatan } \\
\text { rekam medis dokter, dokter gigi dan tenaga } \\
\text { kesehatan dapat melakukan pembetulan dengan } \\
\text { cara mencoret } 1 \text { garis, diparaf dan diberi tanggal. }\end{array}$ & & $\sqrt{ }$ \\
\hline
\end{tabular}

Hasil observasi yang dilakukan oleh peneliti juga sejalan dengan hasil wawancara dengan salah satu informan. Berikut kutipan wawancara dari salah satu informan:

"penyusunan berkasnya ya diruangan ini, berkasnya itu biasanya langsung kami susun kalo stok formulirnya masuk. Tinggal kami satuin ajanya terus kami hekter. biasanya setiap 3 bulan sekali ada masuk stok formulirnya. Kalau misalnya stoknya udah mau habis, ya kami tinggal ngelapor aja kebagian gudang. Jadi kalau nanti ada pasien yang mau berobat, tinggal kami ambil formulirnya terus berkasnya kami antar ke poli" (Informan S, 45 tahun, wawancara: 27 Juli 2020).

Pencatatan pengisian berkas rekam medis dilakukan oleh dokter, perawat, bidan dan petugas pemberi asuhan yang bersangkutan setalah pasien selesai mendapatkan pelayanan. Berikut kutipan wawancara salah satu informan:

"disetiap poli itu sudah ada petugasnya masing-masing, untuk mencatat formulirnya ada sekaligus membantu dokter di poli, untuk mengentry kekomputer juga sudah ada. Jadi pasti selalu diisi sama mereka berkasnya. Habis pasiennya diperiksa langsung diisi biar nanti nggak kelupaan. gitu juga untuk rawat inap. Setiap kali dokternya visit keruangan pasti langsung diisi catatan keperawatannya, jadi jarang yang nggak diisi” (Informan R, 41 tahun, wawancara: 27 Juli 2020).

Formulir rawat jalan di Puskesmas Pangkalan Berandan terdapat 2 lembar sedangkan untuk rawat inap terdapat 5 formulir. Formulir untuk pasien BPJS dan Umum dibedakan. Berikut kutipan wawancara salah satu informan:

"formulirnya ya ini. kalau untuk rawat jalan cuman 2 lembar, lembar pertama untuk anamnese pemeriksaan fisik terus dibelakangnya ini data rekam medisnya kayak catatan keperawatan gitu yang membedakan BPJS dan Umum hanya diwarnanya saja. Kalau BPJS formulir data rekam medisnya biru kalau Umum putih gini" (Informan S, 45 tahun, wawancara: 27 Juli 2020). 
"rawat jalannya cuman dua lembar ini kalau formulir rawat inapnya Ada 5 formulir ini, sama kek yang dibilang ibu tadi form BPJS sama Umum dibedain, rawat inap juga gitu BPJS ada formulir pernyataan peserta, lembar bukti pelayanan rawat inap, resume medis, catatan perawat sama catatan pemakaian obat. Kalau umum hampir sama ajanya cuman beda diisi surat pernyataannya aja." (Informan MR, 44 tahun, wawancara: 27 Juli 2020).

Dalam hal kesalahan pencatatan berkas rekam medis, pembetulan pencatatan dilakukan dengan menggunakan stip-ex. Berikut kutipan wawancara salah satu informasi:

"kalau misalnya salah ya tinggal dihapus aja pakek stip-ex terus dicatat ulang lagi" (Informan S, 45 tahun, wawancara: 27 Juli 2020).

Tabel 7. Hasil Observasi Penyimpanan di Puskesmas Pangkalan Berandan

\begin{tabular}{|c|c|c|c|c|}
\hline No & Pengamatan & Keterangan & Ya & Tidak \\
\hline \multirow{7}{*}{5} & \multirow{7}{*}{ Penyimpanan } & $\begin{array}{l}\text { Adanya SOP yang memandu dalam pemrosesan } \\
\text { penyimpanan rekam medis di Puskesmas Pangkalan } \\
\text { Berandan }\end{array}$ & $\sqrt{ }$ & \\
\hline & & $\begin{array}{l}\text { Sistem penyimpanan berkas rekam medis di } \\
\text { Puskesmas Pangkalan Berandan menggunakan } \\
\text { sistem sentralisasi. }\end{array}$ & $\sqrt{ }$ & \\
\hline & & $\begin{array}{l}\text { Adanya petunjuk nomor rekam medis di ruang } \\
\text { penyimpanan. }\end{array}$ & $\sqrt{ }$ & \\
\hline & & $\begin{array}{l}\text { Sistem penjajaran pada penyimpanan menggunakan } \\
\text { sistem angka langsung (Straight numerical filing). }\end{array}$ & $\sqrt{ }$ & \\
\hline & & $\begin{array}{l}\text { Digunakannya tracer sebagai alat bantu pengganti } \\
\text { berkas yang diambil dari rak penyimpanan. }\end{array}$ & & $\sqrt{ }$ \\
\hline & & $\begin{array}{l}\text { Dilakukannya retensi pada penyimpanan setiap } 2 \\
\text { tahun sekali pada berkas rekam medis. }\end{array}$ & $\sqrt{ }$ & \\
\hline & & $\begin{array}{l}\text { Dilakukannya pemindahan berkas rekam medis aktif } \\
\text { ke inaktif. }\end{array}$ & $\sqrt{ }$ & \\
\hline
\end{tabular}

Hasil observasi yang dilakukan oleh peneliti juga sejalan dengan hasil wawancara dengan salah satu informan. Berikut kutipan wawancara dari salah satu informan :

"ada SOPnya, hanya SOP untuk kode-kode itulah berarti yang enggak ada. Selebihnya lengkap semua SOPnya ibu lihat" (Informan HS, 44 tahun, wawancara: 27 Juli 2020).

Untuk proses penyimpanan berkas rekam medis di Puskesmas Pangkalan Berandan. Berikut kutipan wawancara dari salah satu informan:

"nanti kalau udah selesai pelayanan dikembalikan lagi sama petugas polinya kesini. Yaudah tinggal kami susun sesuai nomor rekam medisnya. Kalau untuk rawat inap baru beda, itu disimpannya dekat UGD sana enggak dirawat jalan nyimpan statusnya” (Informan JA, 53 tahun, wawancara: 27 Juli 2020).

Pada proses peminjaman di Puskesmas Pangkalan Berandan tidak digunakan alat bantu Tracer. Berikut kutipan wawancara dari salah satu Informan:

"mana ada kami pakai-pakai yang kek begituan, kan kami tau siapa orangnya yang minjam. Orang disini-sini ajanya ruangannya" (Informan R, 41 tahun, wawancara: 27 Juli 2020).

Sedangkan untuk proses Retensi di Puskesmas Pangkalan Berandan pernah dilakukan pada tahun 2018. Berikut kutipan wawancara :

"untuk berkas yang lama dan rusak itu kami letakkan di gudang. Sebelum akreditas itulah kami memperbaiki semuanya. Kami pilih-pilih mana berkas yang udah lama terus kami letak digudang belakang. Kalau untuk sekarang ya nggak pernah kami 
pilih-pilih lagi, paling nanti tahun depan waktu mau akreditasi” (Informan MR, 44 tahun, wawancara: 27 Juli 2020).

\subsection{Pembahasan}

\section{Pendaftaran}

Proses pendaftaran menurut standar akreditas Puskesmas Edisi Kedua, versi tahun 2019 terdapat pada standar 3.2 yang menyatakan Proses Pendaftaran Pasien dilaksanakan dengan memperhatikan kebutuhan pelanggan dan kesalamatan pasien, memiliki 3 kriteria yaitu kriteria 3.2.1 Pendaftaran dilaksanakan dengan efektif dan efisien sesuai dengan kebutuhan pelanggan, informasi tentang pendaftaran dan fasilitas rujukan tersedia pada waktu pendaftaran; kriteria 3.2.2 Pasien dengan kendala dan atau berkebutuhan khusus diidentifikasi dan difasilitasi agar dapat memperoleh pelayanan klinis yang optimal; dan kriteria 3.2.3 pasien gawat darurat diberikan prioritas untuk asesmen sebagai bentuk pelaksanaan triase. Proses pendaftaran di Puskesmas Pangkalan Berandan belum semuanya dilaksanakan sesuai dengan elemen penilaian yang terdapat pada Instrumen Akreditas Puskesmas Edisi Kedua, versi tahun 2019. Pada proses pendaftaran rawat jalan telah ditetapkannya pedoman dan prosedur pendaftaran serta adanya bagan alur rawat jalan dan Unit Gawat Darurat (UGD) yang dapat memudahkan pasien dalam melakukan proses pendaftaran sedangkan untuk proses pendaftaran rawat inap belum memiliki pedoman dalam pelaksanannya.

\section{Pengkodingan}

Pengkodingan berkas rekam medis menurut standar akreditas Puskesmas terdapat pada kriteria 3.8.1 yang menyatakan ada pembakuan kode klasifikasi diganosis, kode prosedur, simbol dan istilah yang dipakai. Kegiatan pelaksanaan pengkodingan di Puskesmas Pangkalan Berandan masih belum dilaksanakan dengan baik karena belum adanya Standar Operasional Prosedur (SOP) untuk pelaksanaanya. Pengkodingan tidak dilakukan oleh petugas rekam medis tetapi dilakukan oleh seorang dokter dengan menggunakan ICD 10. Hal ini tidak sesuai dengan Keputusan Menteri Kesehatan No.377/Menkes/SK/III/2007 [4] tentang Standar Kompetensi Perekam Medis yang menyatakan perekam medis harus mampu menetapkan kode penyakit dan tindakan dengan tepat sesuai klasifikasi yang diperlukan di Indonesia (ICD-10). Selain itu dokter juga belum pernah mengikuti pelatihan mengenain pengkodingan.

\section{Hak Akses Rekam Medis}

Hak Akses Rekam Medis menurut standar akreditas Puskesmas terdapat pada kriteria 3.8.3 yang menyatakan "Petugas memiliki akses informasi sesuai dengan kebutuhan dan tanggung jawab pekerjaan”. Pelaksanaan Hak Akses Rekam Medis di Puskesmas Pangkalan Berandan sudah memiliki pedoman atau Standar Operasional Prosedur (SOP) dalam pelaksanaanya. Hal ini sudah sesuai dengan elemen penilaian menurut standar akreditas Puskesmas yang menyebutkan bahwa "Ditetapkan kebijakan, prosedur dan hak akses petugas terhadap informasi medis dengan mempertimbangkan tugas, tanggung jawab petugas, kerahasiaan dan keamanan informasi”. Pelaksanaan peminjaman rekam medis di Puskesmas Pangkalan Berandan tidak semuanya dilakukan sesuai dengan pedoman yang telah ditetapkan yaitu tidak dilakukannya pencatatan data peminjaman pada buku peminjaman rekam medis hal ini akan menyulitkan petugas dalam melacak keberadaan berkas rekam medis. Hal ini sesuai dengan pasal 10 Peraturan Menteri Kesehatan Republik Indonesia Nomor 269 Tahun 2008 [5] tentang Rekam Medis yang menjelaskan bahwa informasi tentang identitas, diagnosis, riwayat penyakit, riwayat pemeriksaan dan riwayat pengobatan dapat dibuka dalam hal: untuk kepentingan kesehatan pasien; 
memenuhi permintaan aparatur penegak hukum dalam rangka penegakan hukum atas perintah pengadilan; permintaan dan atau persetujuan sendiri; permintaan institusi/ lembaga berdasarkan ketentuan perundang-undangan; untuk kepentingan penelitian, pendidikan, dan audit medis, sepanjang tidak menyebutkan identitas pasien.

\section{Assembling}

Proses Assembling menurut standar akreditas Puskesmas terdapat pada kriteria 3.8.3 yang menyatakan adanya sistem pengisian informasi klinis secra lengkap dan jelas didalam rekam medis. Pelaksanaan assembling (perakitan) di Puskesmas Pangkalan Berandan dilakukan pada saat stok formulir rekam medis masuk ke ruang pendaftaran hal ini dilakukan agar memudahkan petugas pada saat pasien mendaftar sehingga tidak menyebabkan pasien terlalu lama menunggu. Dalam hal pengisian informasi klinis di Puskesmas Pangkalan Berandan untuk rawat jalan dan rawat inap dilakukan oleh dokter, dokter gigi dan tenaga kesehatan setelah pasien mendapatkan pelayanan klinis serta mencantumkan nama, waktu dan tanda tangan dokter pada saat memberikan pelayanan hal ini dilakukan agar tidak terjadinya kelupaan dan penumpukan berkas rekam medis di ruangan poli sehingga dapat dilakukan pengentryan dan pelaporan dalam SP2TP di Puskesmas Pangkalan Berandan. Hal ini sesuai dengan pasal 5 Peraturan Menteri Kesehatan Republik Indonesia Nomor 269 Tahun 2008 [5] Tentang Rekam Medis yang menjelaskan "Rekam medis harus dibuat segera dan dilengkapi setelah pasien menerima pelayanan dan Setiap pencatatan ke dalam rekam medis harus dibubuhi nama, waktu dan tanda tangan dokter, dokter gigi atau tenaga kesehatan tertentu yang memberikan pelayanan kesehatan secara langsung”.

\section{Penyimpanan}

Proses penyimpanan menurut standar akreditas Puskesmas terdapat pada kriteria 3.8.4 yang menyatakan "Adanya sistem yang memandu penyimpanan dan pemrosesan rekam medis". Pelaksanaan sistem penyimpanan berkas rekam medis di Puskesmas Pangkalan Berandan tidak menggunakan sistem sentralisasi tetapi menggunaka sistem desentralisasi yaitu sistem penyimpanan dengan cara memisahkan formulir rekam medis milik pasien dimana dokumen rekam medis rawat jalan, rawat inap, gawat darurat, milik seorang pasien dipisahkan pada folder (map) yang berbeda. Sistem penyimpanan rawat inap disimpan dekat dengan ruang UGD hal ini dilakukan agar dapat memudahkan petugas dalam mengambil dan menyimpan berkas rekam medisnya. Sistem penjajaran pada penyimpanan dilakukan menggunakan sistem angka langsung (Straight numerical filing). Namun sistem penjajaran ini sudah tidak banyak digunakan. Penelitian yang dilakukan Ratna Sari [6] menyatakan bahwa Terminal Numerical System lebih banyak digunakan pada saat ini karena banyak digunakan untuk berkas rekam medis dalam jumlah besar, di era JKN pasien harus berobat sesuai dengan tingkatan yang berjenjang yaitu tingkat primer atau pelayanan kesehatan dasar fasakes tingkat pertama terlebih dahulu yaitu Puskesmas sehingga hal ini akan menyebabkan banyak pasien yang berobat ke Puskesmas, tentu ini akan mengakibatkan pasien bertambah banyak.

\section{KESIMPULAN}

Dari hasil penelitian yang dilakukan oleh peneliti mengenai Tinjauan Sistem Penyelenggaraan Rekam Medis Menurut Standar Akreditas Puskesmas di Puskesmas Pangkalan Berandan Tahun 2020 didapatkan kesimpulan sebagai berikut :

1. Proses pendaftaran di Puskesmas Pangkalan Berandan belum semuanya dilakukan sesuai dengan elemen penilaian menurut standar akreditas Puskesmas.

2. Pengkodingan di Puskemas Pangkalan Berandan belum dilakukan sesuai dengan elemen penilaian menurut standar akreditas puskesmas pada kriteria 3.8.1. 
3. Hak Akses Rekam Medis di Puskesmas Pangkalan Berandan telah ditetapkan kebijakan dan pedoman dan prosedur tentang peminjaman berkas rekam medis hal ini sesuai dengan elemen penilaian menurut standar akreditas yang terdapat pada kriteria 3.8.2.

4. Assembling di Puskesmas Pangkalan Berandan belum semuanya mengikuti elemen penilaian menurut standar akreditas Puskesmas yang terdapat pada kriteria 3.8.3.

5. Penyimpan di Puskesmas Pangkalan Berandan menunjukkan bahwa adanya sistem yang memandu penyimpanan dan pemrosesan rekam medis hal ini telah sesuai dengan elemen penilaian menurut standar akreditas Puskesmas pada kriteria 3.8.4.

\section{REFERENCES}

[1] Departemen Kesehatan Republik Indonesia, Peraturan Menteri Kesehatan Republik Indonesia Nomor 43 tahun 2019 tentang Pusat Kesehatan Masyarakat. Jakarta: Departemen Kesehatan RI, 2019.

[2] Departemen Kesehatan Republik Indonesia, Peraturan Menteri Kesehatan Republik Indonesia Lampiran I tentang Standar dan Instrumen Akreditas Puskesmas Edisi Kedua, versi 2019. Jakarta: Departemen Kesehatan RI, 2019.

[3] Salim and Syahrum, Metodologi Penelitian Kualitatif. Bandung: Citapustaka Media, 2012.

[4] Departemen Kesehatan Republik Indonesia, Keputusan Menteri Kesehatan Republik Indonesia Nomor:377/Menkes/SK/III/2007 tentang Standar Profesi Perekam Medis dan Informasi Kesehatan. Jakarta: Departemen Kesehatan RI, 2007.

[5] Departemen Kesehatan Republik Indonesia, Peraturan Menteri Kesehatan Republik Indonesia No: 269/MENKES/PER/III/2008 tentang Rekam Medis. Departemen Kesehatan RI, 2008.

[6] R. A. N and S. S, "Sistem Informasi Rekam Medis di Bagian Filling di Rumah Sakit Umum Daerah Dr. Moewardi," J. Manaj. Inf. Kesehat., vol. 4, no. 1, April 2016, pp. 73-78, 2016.

\section{BIOGRAPHIES OF AUTHORS}

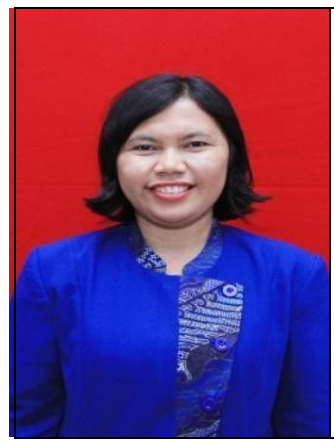

Esraida Simanjuntak, Gelar D-III diperoleh dari Akademi Keperawatan Pemkab Tapanuli Utara, Jurusan Keperawatan pada tahun 2006, Gelar Sarjana diperoleh dari Universitas Sumatera Utara, Fakultas Kesehatan Masyarakat tahun 2009, Magister Kesehatan diperoleh dari Universitas Sumatera Utara, jurusan Ilmu Kesehatan Masyarakat pada tahun 2017. Saat ini aktif sebagai dosen tetap di Prodi D3 Perekam dan Informasi Kesehatan Universitas Imelda Medan dan menjabat sebagai sekretaris Prodi. 